\title{
Control of Battery Charger for Electric Vehicles
}

\section{Quang-Tho Tran*, Vinh-Quan Nguyen, Chi-Nhan Nguyen, Van-Hien Truong}

FEEE, HCMC University of Technology and Education, HCM city, Vietnam

Email: trquangtho@yahoo.com

*Corresponding author

Received: 20 Nov 2020; Received in revised form: 08 Dec 2020; Accepted: 15 Dec 2020; Available online: 21 Dec 2020

(C)2020 The Author(s). Published by Infogain Publication. This is an open access article under the CC BY license

(https://creativecommons.org/licenses/by/4.0/).

\begin{abstract}
The increasing environmental pollution caused by fossil fuel emissions from vehicles using internal combustion engines has spurred the development of electric vehicles. The power sources for the electric vehicles to operate are often stored in different types of batteries with different charging requirements. Most batteries are charged from the grid sources through AC/DC converters for charging battery packs. An effective charging system usually consists of a rectifier and a dual-active bridge (DAB). A typical controller consists of the control of DC bus, PFC (power factor correction), constant voltage $(C V)$, and constant current (CC) for the battery. However, most conventional chargers only regulate the voltage or current of the battery when charging. These types are mainly suitable for lead acid types and the power factor correction has not been considered. Meanwhile, new generation battery packs as lithium-ion batteries require charge of CC at first. When the battery charging voltage reaches a certain voltage threshold, then switch to the mode of $C V$ charge. Basing on the analysis of the battery charging requirements of electric vehicles, this paper presents a battery charger control solution with capability of $C C$ and $C V$ control as well as high power factor. The simulation results on MATLAB/Simulink have validated the effectiveness of the presented method.
\end{abstract}

Keywords - Vehicle battery charger, power factor correction (PFC), dual-active bridge (DAB), constant current $(C C)$, constant voltage $(C V)$.

\section{INTRODUCTION}

The increasing environmental pollution caused by fossil fuel emissions from vehicles has spurred the development of electric vehicles [1]. Vehicle electrification is one of the most potentially viable ways to reduce emissions into the environment. The popularity of electric vehicles in the future will significantly impact many different sectors, especially the power grid. Many developed countries have implemented policies to promote electric vehicle deployment, making use of electric vehicles in recent years more and more popular [2]. The operating energy of electric vehicles is usually stored in battery packs, which are in the direct current form. Therefore, chargers are required to convert the $\mathrm{AC}$ power of the grid to the $\mathrm{DC}$ power to charge the battery packs. The development of electric vehicles has also made the battery and charger technology significantly improved [3] due to the strong investment of car manufacturers. Although electric vehicles have active economic and environmental contributions, however, electric vehicle battery chargers have had a negative impact on the operation of the existing grid [4] - [7]. These impacts mainly cause the peak loads for the power systems during the day. Therefore, battery chargers play an important role in electric vehicle development, charging capacity and charging time will directly affect battery life. Battery charger requirements should have high efficiency and reliability, low cost, light weight, and safety in operation. Electric vehicle chargers must ensure a low current harmonic distortion to minimize negative impact on power quality and a high-power factor to maximize the active power available from the grid.

The power sources for the electric vehicles to operate are often stored through different types of batteries with different charging requirements. The main type of battery used today is lithium-ion [8]. This type of battery has advantages such as high energy density, light weight, low cost, non-toxic, and can use fast charging technology. However, the biggest obstacle to this type of battery is that it can cause an explosion if the charging specifications are inadequate. One of the most important factors in charging 
is temperature. It can easily lead to fire [9] if the charge is not well controlled. In addition, the high temperature during charging also makes the process of alternating solid electrolysis layers faster. This leads to an increase in the internal resistance of the battery, so the storage capacity and life of the battery are also significantly reduced [10].

Despite the negative effects on the grid, the popularity of electric vehicle battery charging systems could also provide active benefits to a vehicle-to-grid (V2G) technology with a good management of this electrical system [11] - [13]. This has confirmed the important role of the charger control for electric vehicles when connecting to the power grid. The principle of a charge system using an AC grid includes the components shown in the block diagram in Fig. 1.

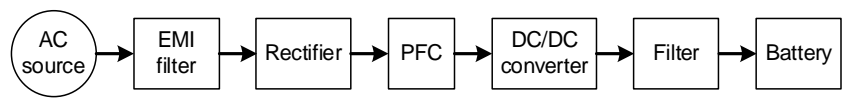

Fig. 1 Block diagram of a charge system

In particular, the input of the charger must usually use an electromagnetic interference filter (EMI filter) to ensure that the harmonics of the charger are not generated into the grid. The rectifier is used to convert AC power of the grid to DC power to charge the battery pack. A PFC (power factor correction) boost circuit is used to increase DC voltage in combination with power factor control for the charger. The DC/DC converter is used to control the charging current and voltage for the battery pack and isolated via a high frequency transformer. The DC/DC converter can be either unidirectional DC/DC converter or bidirectional one. Typically, vehicle-to-grid (V2G) and G2V (grid-to-vehicle) (G2G) chargers require the use of bidirectional converters.

There are many methods to charge electric vehicles [14], this paper focuses on the chargers that attach to the electric vehicle. This form of charging is called on-board battery charger (OBC) [15]. These chargers are commonly used for the BEV (battery electric vehicle). The content of this paper focuses on the control of Level-2 charger for battery packs with a rated voltage of $240 \mathrm{~V}$, charging current up to $80 \mathrm{~A}$, and charging capacity up to $20 \mathrm{~kW}$. The charger is researched to use a single-phase AC input source. The charging system principle is shown in Fig. 2.

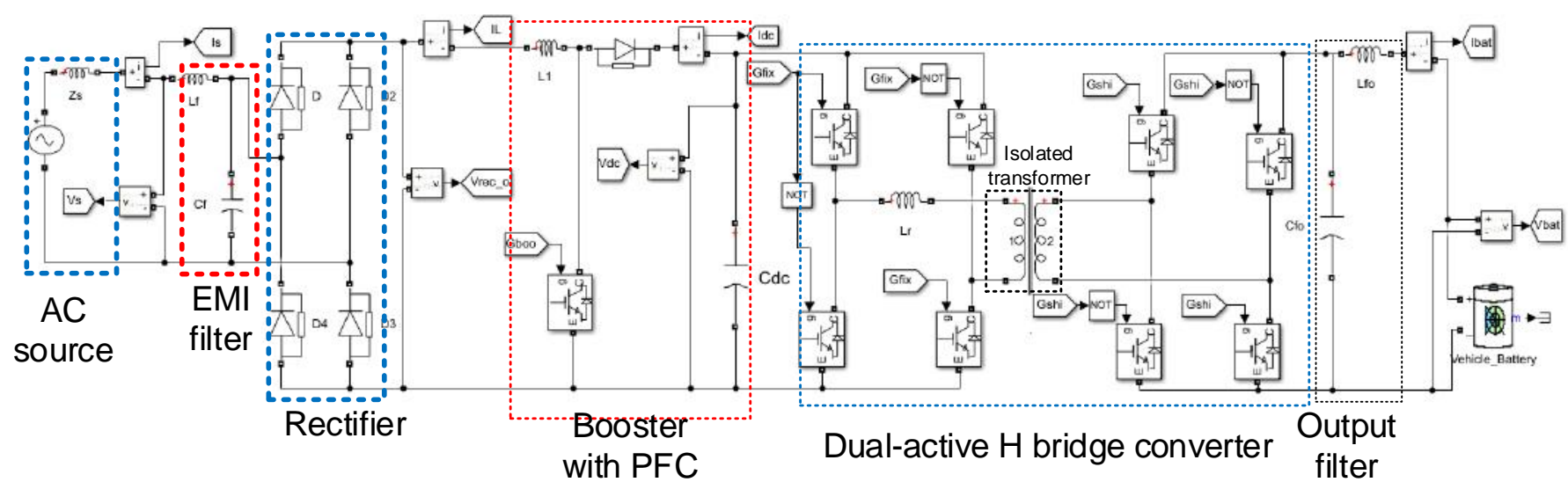

Fig. 2 Principle-diagram of a charge system

\section{CONTROL PRINCIPLE OF CHARGER}

The principle of control for the boost circuit is shown in Fig. 3. In which, the DC voltage and current are regulated by using the PI controllers. The rectifier overcurrent protection is implemented by the current limiter. The PWM pulse width $\mathrm{G}_{\mathrm{boo}}$ of the booster transistor is modulated by comparing the carriers with the value $D_{\text {booo }}$. The PFC is also implemented by using the waveform $V_{\text {rec_o }}$ after rectifying to produce the dc reference current. Then, the waveforms of the $\mathrm{AC}$ input current and voltage are shown in Fig. 4. In order to charge the battery using the DAB converter, the phase shift method is used in this paper. Then, the primary and secondary voltages of the isolated transformer are defined as follows.

$$
\begin{aligned}
& V_{p r}=\frac{4 * V_{1}}{\pi \sqrt{2}}=\frac{4 * V_{d c}}{\pi \sqrt{2}} \\
& V_{s e}=\frac{4 * V_{2}}{\pi \sqrt{2}}=\frac{4 * V_{b a t}}{\pi \sqrt{2}}
\end{aligned}
$$

Thus, the power transferred to the battery is defined as:

$P=\frac{8 * V_{d c} * V_{b a t}}{\pi^{2} * X_{L r}} \sin \alpha$

Where $\alpha$ is the phase shift angle between PWM pulses of primary and secondary transistors of the isolated transformer. The change of charge voltage $\Delta \mathrm{V}_{\text {bat }}$ using the $\mathrm{DAB}$ converter is also defined as follows. 
$\Delta V_{b a t} \approx \frac{8 * R_{\text {Load }} * V_{d c} * \cos \alpha}{\pi^{2} * X_{L r}} * \Delta \alpha=C_{V} * \Delta \alpha$

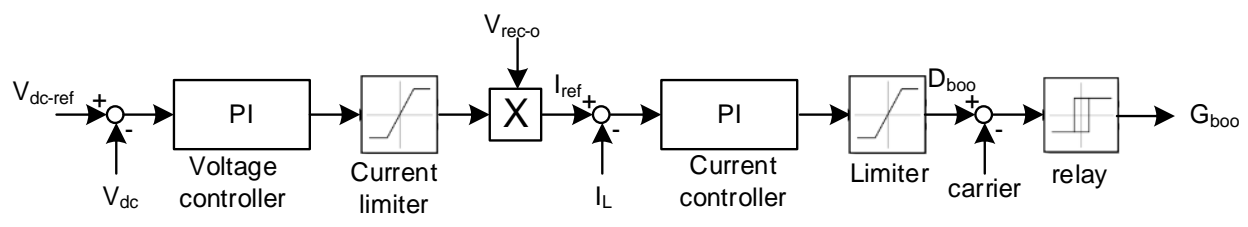

Fig. 3 Control diagram of boost circuit

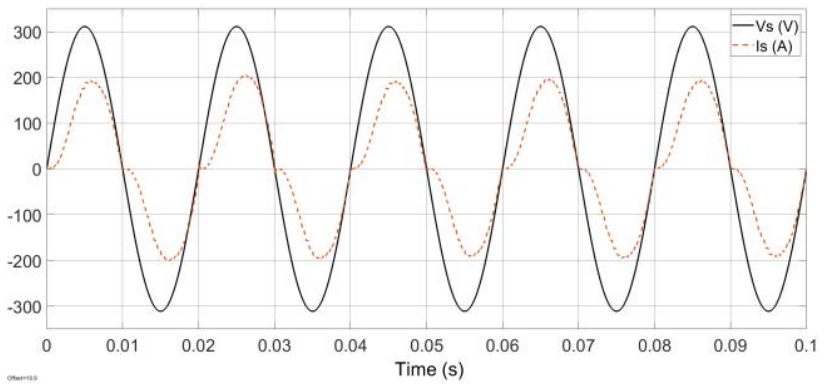

Fig. 4 Grid voltage and current waveforms of charger

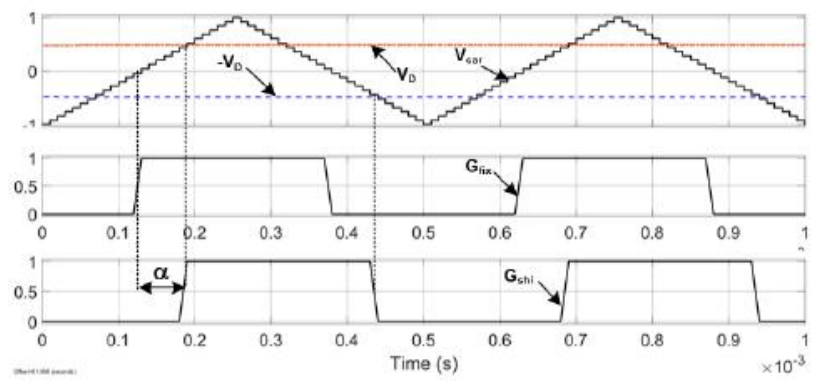

Fig. 5 PWM pulses of DAB converter

Where $\mathrm{R}_{\mathrm{Load}}$ is an equivalent load resistor of the battery. $\mathrm{X}_{\mathrm{Lr}}$ is the reactance of power transfer circuit.

$\Delta I_{b a t} \approx \frac{8 * V_{d c} * \cos \alpha}{\pi^{2} * X_{L r}} * \Delta \alpha=C_{I} * \Delta \alpha$

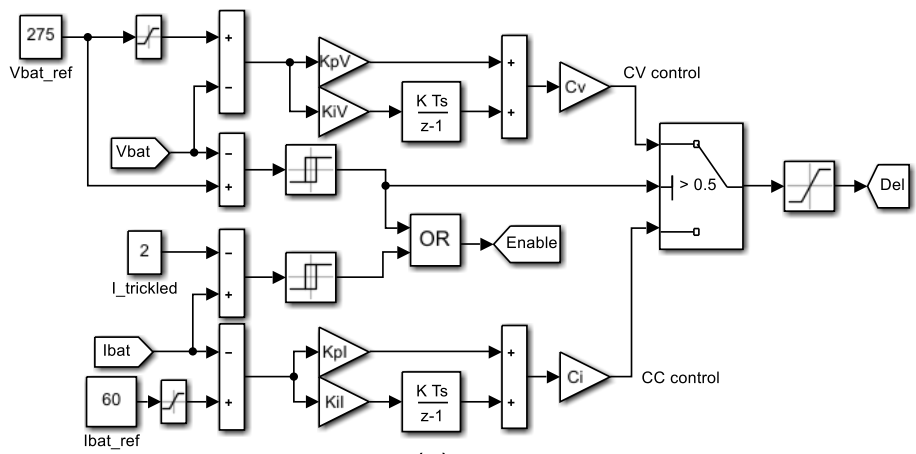

(a)

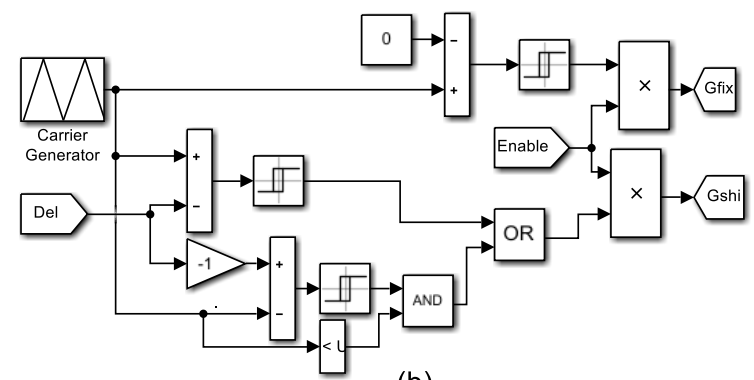

(b)

Fig. 6 PWM pulse generation for shifting the phase angle

Similarly, the charging current is also controlled according to the phase shift angle $\alpha$ basing on (5). The control principle of the phase shift angle is shown in Figs. 5-6.
Regularly, the CC charge is applied for the first stage and the $\mathrm{CV}$ charge is adopted for the second one as Fig. 7 when the battery voltage reaches a defined value. 


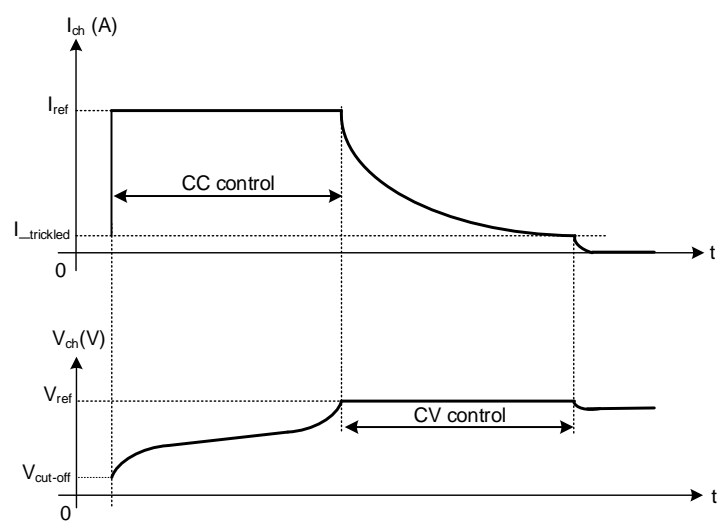

Fig. 7 Charging voltage and current characteristics

Table I. Parameters of battery cells

\begin{tabular}{|l|l|}
\hline \multicolumn{1}{|c|}{ Description } & \multicolumn{1}{c|}{ Value } \\
\hline Normal voltage & $1.18 * \mathrm{Nb} \_s e r$ \\
\hline Rated capacity & $6.5 * \mathrm{Nb} \_$par \\
\hline Fully charged voltage & $1.39 * \mathrm{Nb} \_$ser \\
\hline Nominal discharge current & $1.3 * \mathrm{Nb} \_$par \\
\hline Internal resistance & $0.002 * \mathrm{Nb} \_s e r / \mathrm{Nb} \_$par \\
\hline $\begin{array}{l}\text { Capacity at nominal } \\
\text { voltage }\end{array}$ & $6.25 * \mathrm{Nb} \_$par \\
\hline Exponential zone & $1.28 * \mathrm{Nb}$ _ser, $1.3 *$ \\
& $\mathrm{Nb}$ *par \\
\hline
\end{tabular}

The rechargeable batteries in this paper use the model of parallel and serial coupling of Panasonic lithium-ion battery cells [16]-[21] according to the parameters as shown in Table I. According to the charging standard Level-2, the full charged voltage is up to $275 \mathrm{~V}$ and charging current is up to $80 \mathrm{~A}$. Therefore, the number of cells will be selected as 198 in series and 6 in parallel, respectively.

\section{SIMULATION RESULTS}

The parameters of the charge system are given in Table II. The simulation results are also showed in Figs. 8-13 with three different reference currents as $40 \mathrm{~A}, 60 \mathrm{~A}$, and $80 \mathrm{~A}$, respectively.
Table II. The system parameters

\begin{tabular}{|l|c|}
\hline \multicolumn{1}{|c|}{ Description } & Value \\
\hline Nominal voltage & $233.6 \mathrm{~V}$ \\
\hline Rated capacity & $37.5 \mathrm{Ah}$ \\
\hline SoC & $20 \%$ \\
\hline Booster voltage controller & $\mathrm{Kp}=5 \mathrm{e}-4 ; \mathrm{Ki}=5 \mathrm{e}-3$ \\
\hline Booster current controller & $\mathrm{Kp}=1 \mathrm{e}-2 ; \mathrm{Ki}=1 \mathrm{e}-1$ \\
\hline DAB voltage controller & $\mathrm{Kp}=1 \mathrm{e}-2 ; \mathrm{Ki}=1 \mathrm{e}-2$ \\
\hline DAB current controller & $\mathrm{Kp}=1 \mathrm{e}-2 ; \mathrm{Ki}=1 \mathrm{e}-1$ \\
\hline $\mathrm{C}_{\mathrm{I}}$ & 18.8 \\
\hline $\mathrm{C}_{\mathrm{v}}$ & 112.8 \\
\hline
\end{tabular}

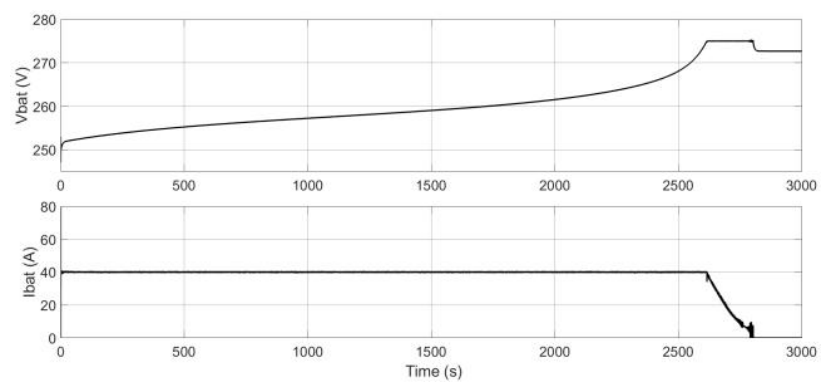

Fig. 8 Charging voltage and current with $I_{r e f}=40 A$

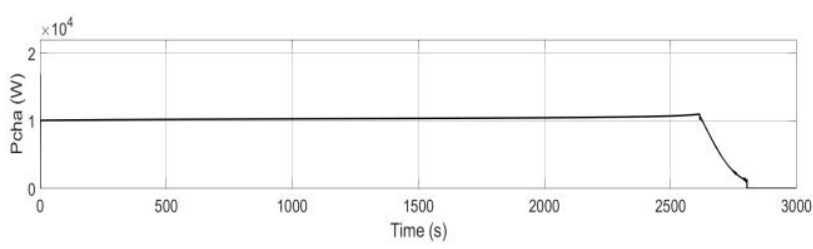

Fig. 9 Charging power with $I_{r e f}=40 A$

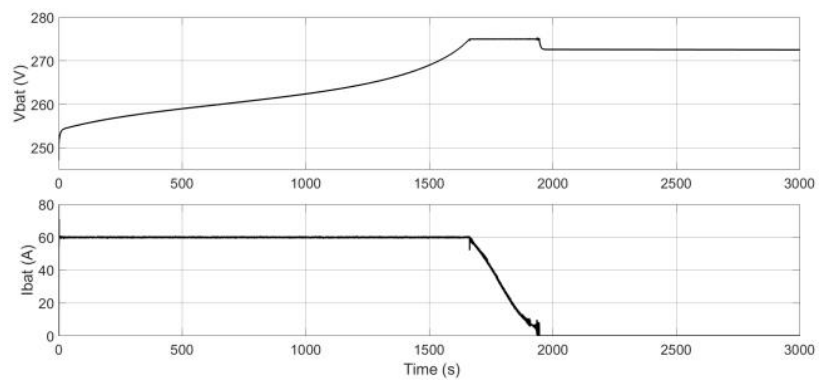

Fig. 10 Charging voltage and current with $I_{\text {ref }}=60 \mathrm{~A}$

The first stage of the charge process is the constant current (CC). When the charging voltage is up to $275 \mathrm{~V}$, the second stage, the constant voltage $(\mathrm{CV})$, is used to charge the battery until the charging current decreases to a trickled current, the charge process will stop. 
When using the reference current of $40 \mathrm{~A}$, the characteristics of charging voltage and current are shown in Fig. 8. Then, the charging power is about $10 \mathrm{~kW}$ and shown in Fig. 9. This makes the charger spend about 2800 $\mathrm{s}$ to finish the charge process.

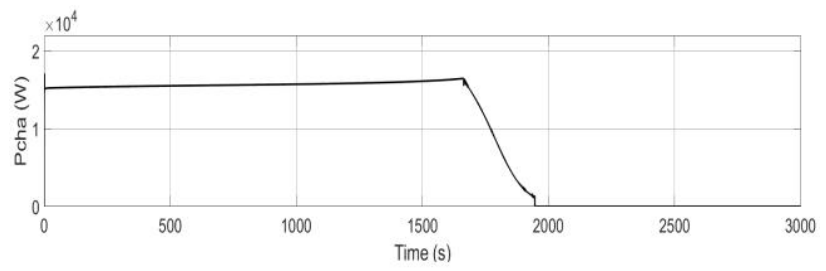

Fig. 11 Charging power with $I_{\text {ref }}=60 \mathrm{~A}$

Similarly, when the reference current of the CC control is $60 \mathrm{~A}$, the characteristics of charging voltage and current are shown in Fig. 10 and the charging power is about 15 $\mathrm{kW}$ and shown in Fig. 11. In this case, the charger only spends about $1950 \mathrm{~s}$ to complete the process of charge.

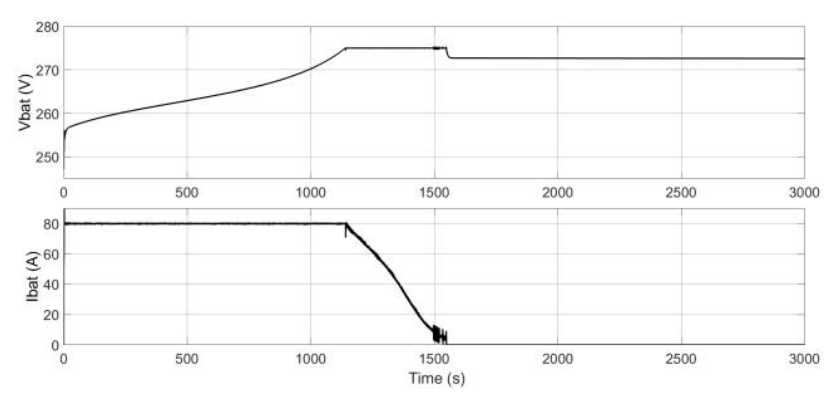

Fig. 12 Charging voltage and current with $I_{r e f}=80 A$

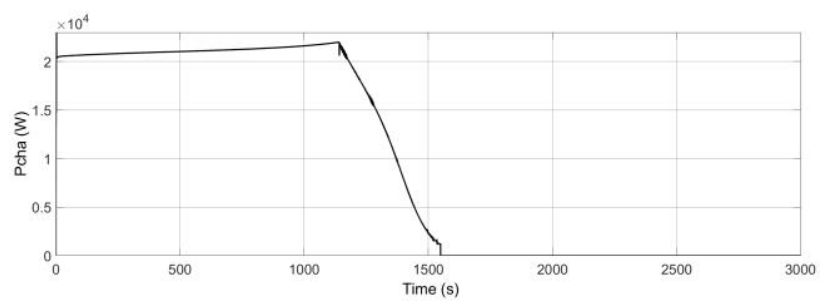

Fig. 13 Charging power with $I_{\text {ref }}=80 \mathrm{~A}$

When the reference current is as $80 \mathrm{~A}$, the charging power is greater than $20 \mathrm{~kW}$. The charger only takes $1550 \mathrm{~s}$ to stop the charge process.

Therefore, the higher charging current the shorter time the charger takes. However, the high charging current also makes the temperature of the charger increase. This can cause fire and explosion.

Thus, the users can choose the suitable charge mode depending on the specific requirements.

\section{CONCLUSION}

This paper has presented a method for controlling the electric vehicle battery charger. The charger control method is based on the DAB converter with the isolated transformer. The control of constant current or constant voltage is relied on the pulses phase shift of DAB converter. The charge process has two stages. In the first stage, the method of constant current is used to control the charger. In the second one, the constant voltage method is used to control the charger until the trickled current, the charge process will end. The effectiveness of the control method has also confirmed basing on the simulation results on MATLAB/Simulink. In addition, the PFC has also considered in the control of the boost circuit. This helps the charger achieve the power factor of unity.

\section{ACKNOWLEDGEMENTS}

This work belongs to the project grant No: T2020-31TĐ. funded by Ho Chi Minh City University of Technology and Education, Vietnam.

\section{REFERENCES}

[1] R. Teodorescu, M. Liserre, and P. Rodriguez, Grid Converters for Photovoltaic and Wind Power Systems. 2011.

[2] Z. Darabi and M. Ferdowsi, "Aggregated impact of plug-in hybrid electric vehicles on electricity demand profile," IEEE Transactions on Sustainable Energy, vol. 2, no. 4. pp. 501-508, 2011, doi: 10.1109/TSTE.2011.2158123.

[3] N. Imanishi and O. Yamamoto, "Rechargeable lithium-air batteries: characteristics and prospects," Mater. Today, vol. 17, no. 1, pp. 24-30, 2014, [Online]. Available: https://www.sciencedirect.com/science/article/pii/S136970 2113004586.

[4] J. Y. Yong, V. K. Ramachandaramurthy, K. M. Tan, and N. Mithulananthan, "A review on the state-of-the-art technologies of electric vehicle, its impacts and prospects," Renew. Sustain. Energy Rev., vol. 49, pp. 365-385, 2015, [Online]. Available: https://www.sciencedirect.com/science/article/pii/S136970 2113004586.

[5] C. H. Dharmakeerthi, N. Mithulananthan, and T. K. Saha, "Overview of the impacts of plug-in electric vehicles on the power grid," 2011, doi: 10.1109/ISGT-Asia.2011.6167115.

[6] R. C. G. II, L. Wang, and M. Alam, "The impact of plug-in hybrid electric vehicles on distribution networks: A review and outlook," Renew. Sustain. Energy Rev., vol. 15, pp. 544-553, 2011.

[7] M. Aziz and T. Oda, "Simultaneous quick-charging system for electric vehicle," in 9th International Conference on Applied Energy, ICAE2017, 2017, pp. 1811-1816.

[8] Y. Miao, P. Hynan, A. Von Jouanne, and A. Yokochi, 
"Current li-ion battery technologies in electric vehicles and opportunities for advancements," Energies, vol. 12, no. 6, 2019, doi: 10.3390/en12061074.

[9] P. Sun, R. Bisschop, H. Niu, and X. Huang, "A Review of Battery Fires in Electric Vehicles," Fire Technol., vol. 56, pp. 1361-1410, 2020, doi: 10.1007/s10694-019-00944-3.

[10] V. A. Marcis, A. V. J. S. Praneeth, L. Patnaik, and S. S. Williamson, "Analysis of CT-CV Charging Technique for Lithium-ion and NCM 18650 Cells over Temperature Range," in Proceedings of the IEEE International Conference on Industrial Technology, 2020, vol. 2020-Feb, pp. 947-952, doi: 10.1109/ICIT45562.2020.9067186.

[11] M. A. Masrur et al., "Military-Based Vehicle-to-Grid and Vehicle-to-Vehicle Microgrid - System Architecture and Implementation," IEEE Transactions on Transportation Electrification, vol. 4, no. 1. pp. 157-171, 2017, doi: 10.1109/TTE.2017.2779268.

[12] H. KLAINA, I. PICALlO, P. LOPEZ-ITURRI, J. J. ASTRAIN, and L. AZPILICUETA, "Aggregator to Electric Vehicle LoRaWAN based Communication Analysis in Vehicle-to-Grid Systems in Smart Cities," IEEE Access, 2020.

[13] X. Chen and K.-C. Leung, "Non-cooperative and Cooperative Optimization of Scheduling with Vehicle-toGrid Regulation Services," IEEE Trans. Veh. Technol., vol. 69, no. 1, pp. 114-130, 2020.

[14] M. Yilmaz and P. T. Krein, "Review of battery charger topologies, charging power levels, and infrastructure for plug-in electric and hybrid vehicles," IEEE Transactions on Power Electronics, vol. 28, no. 5. pp. 2151-2169, 2013, doi: 10.1109/TPEL.2012.2212917.

[15] S. Zou, J. Lu, A. Mallik, and A. Khaligh, "Modeling and Optimization of an Integrated Transformer for Electric Vehicle On-Board Charger Applications," IEEE Trans. Transp. Electrif., vol. 4, no. 2, pp. 355-363, 2018.

[16] W. Gao, X. Li, M. Ma, Y. Fu, J. Jiang, and C. Mi, "Case Study of an Electric Vehicle Battery Thermal Runaway and Online Internal Short Circuit Detection," IEEE POWER Electron., vol. 36, no. 3, pp. 2452-2455, 2021.

[17] J. Zhang, L. Zhang, F. Sun, and Z. Wang, “An Overview on Thermal Safety Issues of Lithium-ion Batteries for Electric Vehicle Application," IEEE Access, vol. 6, pp. 23848-23863, 2018.

[18] D. Li, Z. Zhang, P. Liu, Z. Wang, and L. Zhang, "Battery Fault Diagnosis for Electric Vehicles Based on Voltage Abnormality by Combining the Long Short-term Memory Neural Network and the Equivalent Circuit Model," IEEE Trans. Power Electron, vol. 36, no. 2, pp. 1303-1315, 2021.

[19] C. Zhu, X. Li, L. Song, and L. Xiang, "Development of a theoretically based thermal model for lithium ion battery pack," Journal of Power Sources, vol. 223. pp. 155-164, 2013, doi: 10.1016/j.jpowsour.2012.09.035.

[20] L. H. Saw, K. Somasundaram, Y. Ye, and A. A. O. Tay, "Electro-thermal analysis of Lithium Iron Phosphate battery for electric vehicles," Journal of Power Sources, vol. 249. pp. 231-238, 2014, doi: 10.1016/j.jpowsour.2013.10.052.

[21] N. Omar and E. Al, "Lithium iron phosphate based battery - Assessment of the aging parameters and development of cycle life model," Appl. Energy, vol. 113, pp. 1575-1585, 2014. 